\title{
Ginsenoside Re: Its chemistry, metabolism and pharmacokinetics
}

\author{
Dacheng Peng ${ }^{1}$, Huashan Wang ${ }^{2}$, Chenling $\mathrm{Qu}^{3}$, Laihua Xie ${ }^{4^{*}}$, Sheila M Wicks ${ }^{5,6}$ and Jingtian Xie , $^{1,7^{*}}$
}

\begin{abstract}
Ginsenosides, the bioactive components of ginseng, can be divided into two major groups, namely 20(S)protopanaxatriol (e.g. $R e, \mathrm{Rg}_{1}, \mathrm{Rg}_{2}$, and $\mathrm{Rb}_{3}$ ) and 20(S)-protopanaxadiol (e.g. $\mathrm{Rb}_{1}, \mathrm{Rb}_{2}$, $\mathrm{Rc}$, and $\mathrm{Rd}$ ). Biological and environmental factors may affect the content of ginsenosides in different parts of ginseng plant. Evidence from pharmacokinetic and metabolic studies of Re demonstrated that (1) the absorption of Re is fast in gastrointestinal tract; (2) Re may be metabolized mainly to $\mathrm{Rh}_{1}$ and $\mathrm{F}_{1}$ by intestinal microflora before absorption into blood; and

(3) Re is quickly cleared from the body.
\end{abstract}

\section{Background}

Ginseng is a key herb in Chinese medicine, and has a wide range of therapeutic and pharmacological uses [1-3]. Panax ginseng is a slow growing perennial herb of the Araliaceae family usually cultivated in China, Japan, Korea and Russia, as well as in the United States and Canada. Ginseng root has been used as an oriental folk medicine for several thousand years [2,4]. It is a highly valued medicinal plant in the Far East that and also popular in the West in the past 20 years [2,4-7].

A number of studies suggest that both Panax ginseng C.A. Meyer (also known as Asian ginseng, Chinese ginseng or Korea ginseng) and Panax quinquefolius (also known as American ginseng) have multiple components and pharmacological functions [7-14]. Among the complex constituents of ginseng, ginsenosides (also known as ginseng saponins or triterpene saponins) are the major components responsible for biochemical and pharmacological actions of ginseng [9,15-17]. With the development of modern technology, more than 150 naturally occurring ginsenosides have been isolated from Panax species [18]. About 40 ginsenosides have been identified from the root of Panax ginseng [1,19-22].

In order to explore the pharmacological actions, mechanisms and clinical applications of ginseng, some

\footnotetext{
*Correspondence: xiela@umdnj.edu; jingtian.xie@gmail.com

1The Ben May Department for Cancer Research, Pritzker School of Medicine, The University of Chicago, Chicago, IL 60637, USA

${ }^{4}$ Department of Cell Biol \& Mol Med, UMDNJ-New Jersey Medical School,

185 South Orange Ave. MSB C609, Newark, NJ 07103, USA

Full list of author information is available at the end of the article
}

researchers focused on purified individual ginsenosides rather than whole ginseng extracts $[1,23]$. Individual ginsenosides may have different characteristics in chemistry, metabolism, and pharmacokinetics. Ginsenoside Re (Re) belongs to 20(S)-protopanaxatriol group (Figure 1), and is a major ginsenoside in ginseng [7,10,16,22,24-27]. Literature shows that Re exhibits multiple pharmacological activities via different mechanisms $[12,16,28]$. For example, in cardiovascular system, Re possesses negative effects on cardiac contractility and autorhythmicity, anti-arrhythmic and anti-ischemic effects, angiogenic regeneration activities and cardiac electrophysiological functions [28]. Xie et al. and Li et al. [13,29-32] found that the quantity of Re in ginseng leaf and berry is much higher than in ginseng main root and suggested that ginseng leaf-stem could be a valuable source for Re. There have been other new findings in recent years. This article provides an overview of the recent advances in chemistry, metabolism and pharmacokinetics of Re.

\section{Chemistry and content Chemical structure of Re}

$R g_{1}, R c, R d, R e, R b_{1}, R b_{2}$ and $R b_{0}$ are the main ginsenosides in quantity $[1,33]$. The top six major ginsenosides $\left(R b_{1}, R e, R d, R c, R_{1}\right.$ and $\left.R_{3}\right)$ make up over $70 \%$ of total ginsenoside content in P. quinquefolius $[34,35]$.

Ginsenosides are the glycosides that contain aglycone with dammarane (except Ro). Ginsenosides (Figure 2) are generally divided into two groups, namely the protopanaxadiol (PPD) and protopanaxatriol (PPT) ginsenoside groups. The sugar moities in the PPD group
C Biomed Central 


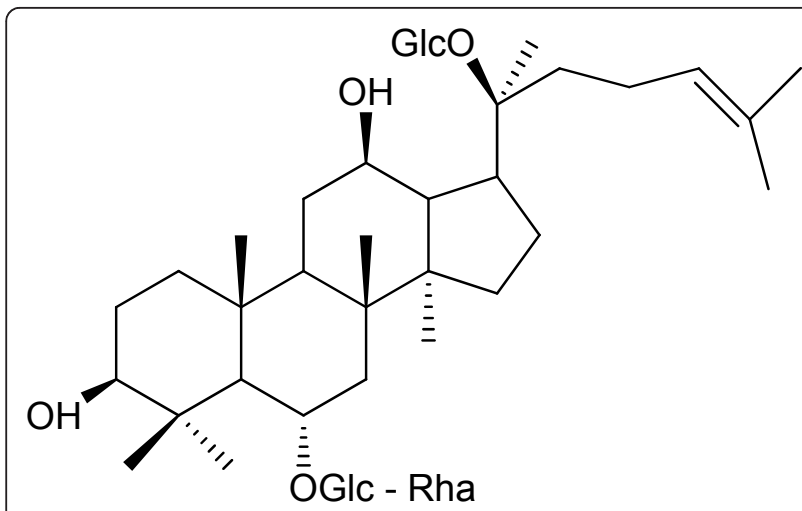

Figure 1 Chemical structure of ginsenoside $\operatorname{Re}(M W=946)$.

including $\mathrm{Rb}_{1}, \mathrm{Rb}_{2}, \mathrm{Rc}, \mathrm{Rd}, \mathrm{Rg}_{3}$ and $\mathrm{Rh}_{3}$, attach to the 3position of dammarane-type triterpine, whereas the sugar moities in the PPT group including $R e, R f, \operatorname{Rg}_{1}$, $\mathrm{Rg}_{2}$ and $\mathrm{Rh}_{1}$, attach to the 6-position of dammaranetype triterpine. A ginsenoside possesses a rigid four trans-ring steroid skeleton with a modified side chain at
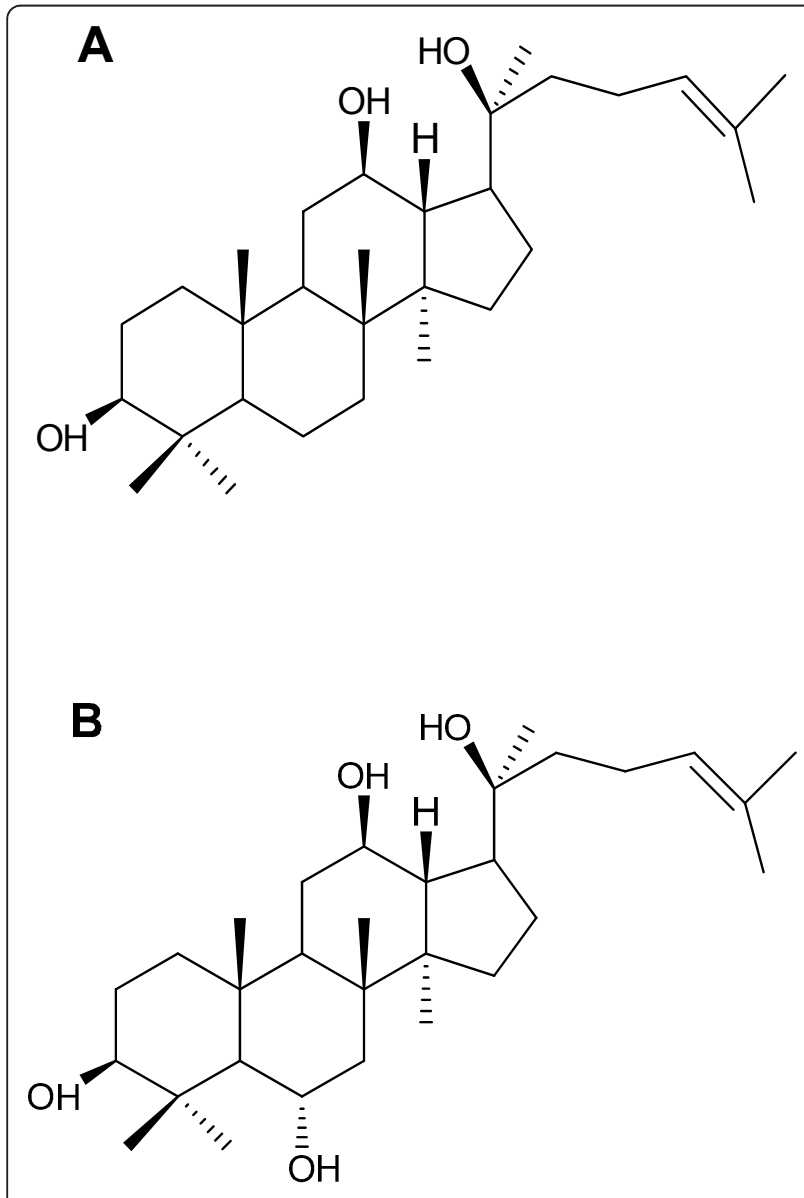

Figure 2 Chemical structures of protopanaxadiol (A) and protopanaxatriol (B).
C-20 [1,17,36-39]. The chemical structures of ginsenosides are different from each other in the number, linkage position and type of sugar [17,39]. During extraction, sugar moieties of ginsenosides may be cleaved by acid hydrolysis or endogenous glycosidases to give corresponding aglycones [25,36]. PPD and PPT may rearrange into panaxadiol and panaxatriol, respectively, to provide artificial ginsenoside products. Kang et al. [40] showed that PPD and PPT ginsenoside groups had different bioactivities, even opposite effects. Recently, Zhu et al. [41] found six new PPT-type ginsenosides extracted from the $P$. ginseng root, named $R_{1}$ to $\operatorname{Re}_{6}$ (compounds 1-6) respectively, along with ten other known PPT ginsenosides.

\section{Content of Re in ginseng}

The biological and environmental factors that may affect the quantity and quality of ginsenosides in ginseng $[14,35]$ include the species, age, part of the plant, season of harvest, method of cultivation, and means of preservation. For example, the content of $R e, R_{1}$ and $R d$ is higher in the wild $P$. ginseng roots than in the cultivated ginseng roots, while the content of $R c, R b_{2}$ and $R b_{1}$ is lower in the wild $P$. ginseng roots than in the cultivated ones. These differences in content of ginsenosides might affect their biological and pharmacological properties. Root ginsenoside content depends on the age of ginseng plant. For example, the plants younger than four years of age are considered unsuitable for harvest due to their low ginsenoside content [35,42-44]. Lim et al. [35] determined the genotypes and environmental factors affecting the ginsenoside content among eight wild populations of $P$. quinquefolius. The influence of genotypes and environment on ginsenoside content varies among different types of ginsenosides. Specifically, the Re content varies with populations but not locations, whereas $R b_{1}, R c$ and $R b_{2}$ only varies with locations, and $\mathrm{Rg}_{1}$ and $\mathrm{Rd}$ varies with both. Ginsenoside levels are decreased, while ginseng growth is increased, at an intensively managed garden location. The content and composition of ginsenosides vary with other environmental conditions such as the type of soil, temperature, light intensity and water content [45].

Using high pressure microwave-assisted extraction (HPMAE) and high-performance liquid chromatography (HPLC) coupled with evaporative light scattering detection (ELSD), i.e. HPMAE HPLC-ELSD, Qu et al. [46] studied the effects of different parts and age of $P$. quinquefolius on the content of 12 ginsenosides, namely $\mathrm{Rg}_{1}$, Re, Rf, $R_{2}, R h_{1}, R_{1}, R c, R b_{2}, R b_{3}, R d, R h_{2}$ and $F_{11}$. The study ranked the parts of five-years-old $P$. quinquefolius in terms of total content of these 12 ginsenosides in a descending order: leaf, root-hair, rhizome, main root and stem, suggesting that the leaf could be a better 
source for ginsenosides, as compared with other parts of ginseng plant. It also found that in ginseng roots, the content of $\mathrm{Re}$ and $\mathrm{Rb}_{1}$, the major ginsenosides, increase with age of the plant.

In a comparative study on the quality of Tongrentang Red Ginseng and Korean Red Ginseng, Wu et al [47] found that the content of $\mathrm{Re}, \operatorname{Rg}_{1}$ and $\mathrm{Rb}_{1}$ in the Tongrentang Red Ginseng is less than the content in the Korean Red Ginseng.

Another extensive study [48] performed a quantitative analysis of $\mathrm{Re}, \mathrm{Rb}_{1}$ and $\mathrm{Rg}_{1}$ in $P$. quinquefolius berry and flower sampled in various months throughout the year, by enzyme-linked immunosorbent assay (ELISA). The $P$. quinquefolius flower had higher content of Re, $\mathrm{Rb}_{1}$ and $\mathrm{Rg}_{1}$ and the lowest content of $\mathrm{Re}$ in the berries harvested in September [48]. To analyze the Re content in $P$. quinquefolius berry pulp extracts, Morinaga et al. [49] performed a new Eastern blot technique with antiRe monoclonal antibody, and confirmed that the content of Re varies from part to part in the plant.

Lee et al. [50] reported the variations in the ginsenoside profiles of ginseng landraces in Korea. They found that the $P$. ginseng wild population exhibits three types of ginsenoside profiles affected by genetic and environmental factors.

\section{Metabolism and pharmacokinetics}

Re has recently been studied extensively [12,13,30]; however, little is known about the metabolic and pharmacokinetic profiles.

\section{Absorption}

After oral administration, $\mathrm{Re}$ is in contact with the gastriointestinal fluids containing gastric acids and gastric enzymes, intestinal enzymes, and colonic bacteria [51,52]. Li et al. [23,53] studied the pharmacokinetic parameters and absolute bioavailability of $\mathrm{Re}, \mathrm{R}_{1}, \mathrm{Rg}_{1}, \mathrm{Rd}$, and $\mathrm{Rb}_{1}$ after oral or intravenous administration of total notoginsenosides. Main pharmacokinetic parameters of these constituents were determined by Drug and Statistics (DAS) for Windows pharmacokinetics software. The results showed that $\mathrm{Re}, \mathrm{R}_{1}, \mathrm{Rg}_{1}$, $\mathrm{Rd}$ and $\mathrm{Rb}_{1}$ reached peak concentration in plasma within about 45 minutes after oral administration of total panax notoginsenoside (TPNG) powder in rats, suggesting a rapid absorption of ginsenosides in gastrointestinal tract. The absolute bioavailability of Re was 7.06\% [53]. To confirm the rapid absorption finding, Joo et al. [27] conducted a pharmacokinetic study using ICR mice and ultra performance liquid chromatography-electrospray ionization-mass spectrometry (UPLCESI-MS) analytical method. This pharmacokinetic study [27] revealed that the time to reach the peak plasma concentration after oral administration was $0.4 \pm 0.2$ hour. The data also showed that the oral bioavailability was
0.19-0.28\%. Qi et al. [54] found that the oral bioavailability of PPD ginsenosides $\left(\mathrm{Ra}_{3}, \mathrm{Rb}_{1}, \mathrm{Rd}, \mathrm{Rg}_{3}\right.$ and $\left.\mathrm{Rh}_{2}\right)$ and PPT ginsenosides $\left(\mathrm{Rg}_{1}, \mathrm{Re}, \mathrm{Rh}_{1}\right.$, and $\left.\mathrm{R}_{1}\right)$ was less than $5 \%$ and PPT ginsenosides had better bioavailability, possibly due to the faster degradation of PPD ginsenosides.

\section{Metabolism and biotransformation}

Han et al. [55] showed that PPT ginsenosides are hydrolyzable to $\mathrm{Rh}_{1}$ under mild acidic conditions. Tabaw et al. [56] found that two degradation products of the PPT ginsenosides, $\mathrm{Rh}_{1}$ and $\mathrm{F}_{1}$ could reach the systemic circulation in humans in addition to compound-K resulting from the stepwise deglycosylation of PPD ginsenosides. Bae et al. [57] further confirmed that the PPT (Re and $\mathrm{Rg}_{1}$ ) could be metabolized mainly to $\mathrm{Rh}_{1}$ and G-F1 in the gastrointestinal tract by intestinal microflora, before absorption into the blood. Chi and Ji et al. [58] tested the biotransformation of $\mathrm{Re}$ and $\mathrm{Rb}_{1}$ by cell extracts from various food-grade edible microorganisms. As shown in Figure 3, Re was transformed into $\mathrm{Rh}_{1}$ via $\mathrm{Rg}_{2}$ by Bif. sp. Int57 and Bif. sp. SJ32; A. niger transformed Re into $\mathrm{Rh}_{1}$ via $\mathrm{Rg}_{1} ;$ A. usamii transformed $\mathrm{Re}$ into $\mathrm{Rg}_{2}$. However, $\mathrm{Rb}_{1}$ was transformed into compound-K and $\mathrm{Rh}_{1}$ by different pathways [58].

Metabolic research of Re in animals was also reported [59]. Six SD rats were used and divided into three groups. Feces were collected at 12, 24, 36, 48 and 60 hours after oral administration of $\operatorname{Re}(100 \mathrm{mg} / \mathrm{kg})$. Six metabolites of Re were detected in the feces of rat. The structures of the metabolites were identified as 20(S)ginsenoside $\mathrm{Rg}_{2}, 20(\mathrm{~S})$-ginsenoside $\mathrm{Rh}_{1}, 20(\mathrm{R})$-ginsenoside $\mathrm{Rh}_{1}$, ginsenoside $\mathrm{F}_{1}, 3$-oxo-ginsenoside $\mathrm{Rh}_{1}$ and PPT. The metabolic pathways of Re in animals were similar to those in humans [59].

A similar metabolic study was also carried out in vivo with HPLC coupled with electrospray ionization and quadrupole time-of-flight tandem mass spectrometry (HPLC-ESI-TOF-MS/MS) [60]. The rat urine samples were collected and pretreated through $\mathrm{C}(18)$ solid-phase extraction cartridges prior to analysis. As a result, eleven and nine metabolites together with Re were detected and identified in rat urine after oral and intravenous administration, respectively. Oxidation and deglycosylation were found to be the major metabolic processes of the constituent in rat, indicating that a large part of the intact ginsenosides was metabolized and transformed to ginsenosides with more biological effects in the gastrointestinal tract [52]. PPT ginsenosides, such as $\mathrm{Re}$ and $\mathrm{Rg}_{1}$, were mainly converted to $\mathrm{Rh}_{1}$ and $\mathrm{F}_{1}$ and then to corresponding aglycones $[51,56]$.

\section{Elimination}

Xia et al. [38] applied a developed and validated liquid chromatography-electrospray ionization-mass spectrometry (LC-ESI-MS) method to detect $\mathrm{Re}, \mathrm{Rg}_{1}, \mathrm{Rd}, \mathrm{Rb}_{1}$ and 

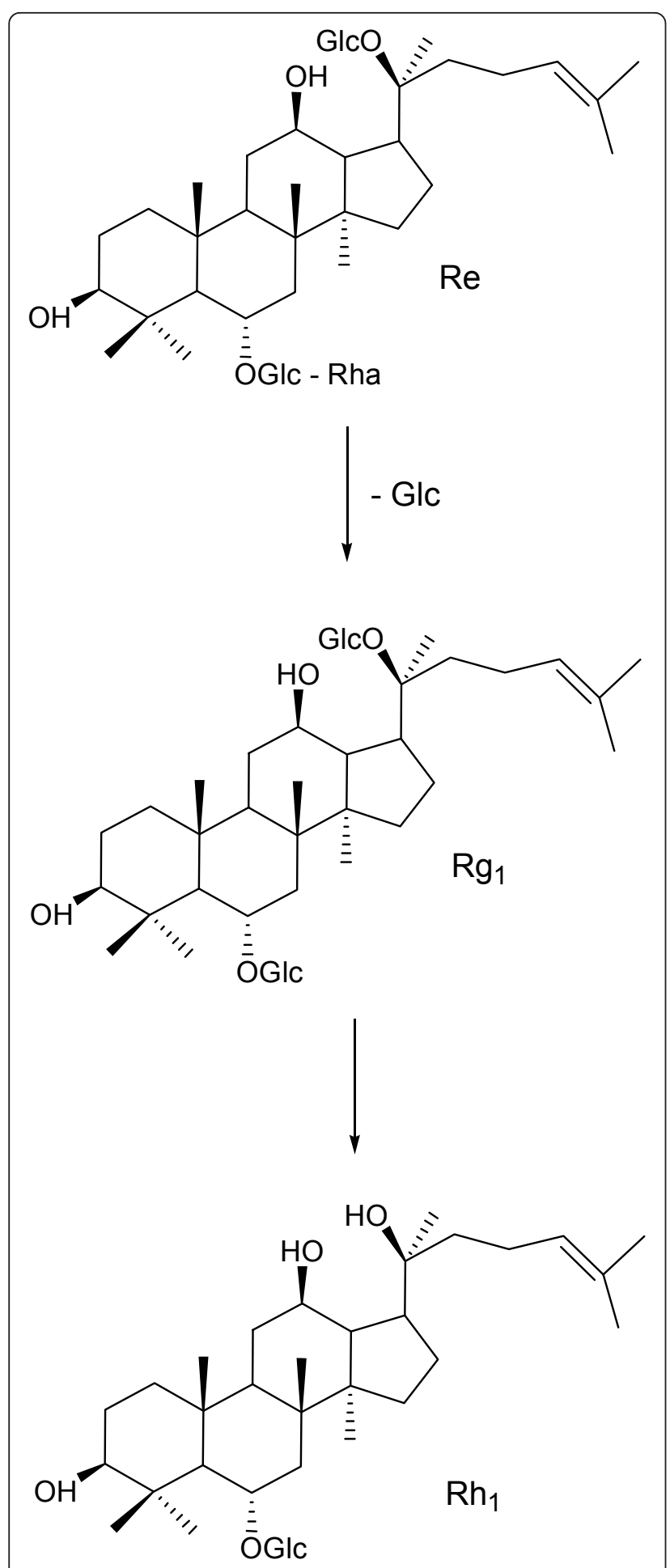

Figure 3 Proposed possible metabolism pathway of G-Re by stomach acidity and large intestine bacteria.

ophiopogonin D in rat plasma. $\operatorname{Re}$ and $\operatorname{Rg}_{1}$ were eliminated quickly from the body. The pharmacokinetic behaviors of $R d$ and $R b_{1}$ were significantly different from those of $\operatorname{Re}$ and $\operatorname{Rg}_{1}$ in rat. Joo et al. [27] found that $\operatorname{Re}$ was rapidly cleared from the body within $0.2 \pm 0.03$ hour for male mice and $0.5 \pm 0.08$ hour for female mice after intravenous administration. They also found that ginseng berry extract exhibited a superior oral absorption of Re as compared to orally fed Re, suggesting that ginseng berry extract may be of choice for Re intake [27].

The plasma concentrations of $\operatorname{Re}$ and $\operatorname{Rg}_{1}$ were determined and the pharmacokinetic parameters were calculated after intravenous Shenmai injection in ten volunteers [61]. The study found the distribution and elimination of $\operatorname{Re}$ and $\mathrm{Rg}_{1}$ to be rapid after intravenous injection; and the pharmacokinetic characteristics could be fitted to the two-compartment model of pharmacokinetics.

\section{Conclusion}

Multiple biological and environmental factors affect the quantity and quality of ginsenosides in ginseng parts. Studies on Re demonstrate that (1) the absorption of Re is quick in rats; (2) PPT, $\mathrm{Re}$ and $\mathrm{Rg}_{1}$, are likely to be metabolized to $\mathrm{Rh}_{1}$ and $\mathrm{F}_{1}$ by intestinal microflora before absorption into the blood; and (3) Re can be quickly eliminated from the body.

\section{Abbreviations}

DAS: Drug and Statistics for Windows pharmacokinetic software; ELISA: enzyme-linked immunosorbent assay; Re: ginsenoside $R e\left(R g_{1}, R g_{2}, R g_{3}, R f\right.$, $R b_{1}, R b_{2}, R b_{3}, R c, R d$, and $R e_{1}-R e_{6}$ are the same abbreviations with $\left.R e\right)$; HPLC-ESI-TOF-MS/MS: high-performance liquid chromatography coupled with electrospray ionization and quadrupole time-of-flight tandem mass spectrometry; HPLC-ELSD: high-performance liquid chromatography coupled with evaporative light scattering detection; HPMAE: high pressure microwave-assisted extraction; PPD: protopanaxadiol; LC-ESI-MS: liquid chromatography-electrospray ionization-mass spectrometry; PPT: protopanaxatriol; TPNG: total Panax notoginsenoside; UPLC/MS: ultra performance liquid chromatography mass spectrometry

\section{Acknowledgements}

The work of LHX is supported by NIH/NHLBI R01 HL97979.

\section{Author details}

${ }^{1}$ The Ben May Department for Cancer Research, Pritzker School of Medicine, The University of Chicago, Chicago, IL 60637, USA. ${ }^{2}$ Section of Emergency Medicine, Pritzker School of Medicine, The University of Chicago, Chicago, IL 60637, USA. ${ }^{3}$ College of Grain Oil and Food Science, Henan University of Technology, 140 Songshan South Road, Zhengzhou 450052, China.

${ }^{4}$ Department of Cell Biol \& Mol Med, UMDNJ-New Jersey Medical School, 185 South Orange Ave. MSB C609, Newark, NJ 07103, USA. ${ }^{5}$ Department of Biological Sciences, City Colleges of Chicago, 1900 W. Van Buren Street, Chicago, IL 50512, USA. ${ }^{6}$ University of Illinois at Chicago, 909 S. Wolcott Ave. Chicago, IL 60612, USA. 'Shangqiu Medical College, 486 W. Beihei Street, Shangqiu, Henan 476000, China.

\section{Authors' contributions}

JTX and LHX conceived study. DCP, HSW, CLQ and SMW collected the data. DCP, HSW, CLQ, LHX, SMW and JTX wrote the manuscript. The authors have read and approved the final version of the manuscript.

\section{Competing interests}

The authors declare that they have no competing interests.

Received: 21 July 2011 Accepted: 7 February 2012

Published: 7 February 2012 


\section{References}

1. Lu JM, Yao Q, Chen C: Ginseng compounds: an update on their molecular mechanisms and medical applications. Curr Vasc Pharmacol 2009, 7(3):293-302

2. Peng DC, Chen WP, Xie JT: Antihyperglycemic effects of ginseng and possible mechanisms. Drugs of the future 2008, 33(6):507-514.

3. Hofseth $\amalg$, Wargovich MJ: Inflammation, cancer, and targets of ginseng. $J$ Nutr 2007, 137(1 Suppl):183S-185S.

4. Chevallier A: Encyclopedia of herbal medicine. New York: DK Publishing Inc; 2000.

5. Blumenthal M, Goldberg A, Brinckmann J: Ginseng root. Newton, MA: Integrative Medicine Communications; 2000.

6. Barnes PM, Powell-Griner E, McFann K, Nahin RL: Complementary and alternative medicine use among adults: United States, 2002. Adv Data 2004, 343:1-19.

7. Helms S: Cancer prevention and therapeutics: Panax ginseng. Altern Med Rev 2004, 9(3):259-274.

8. Hu SY: A contribution to our knowledge of ginseng. Am J Chin Med 1977, 5(1):1-23.

9. Attele AS, Wu JA, Yuan CS: Multiple pharmacological effects of ginseng Biochem Pharmacol 1999, 58:1685-1693.

10. Attele AS, Zhou YP, Xie JT, Wu JA, Zhang L, Dey L, Pugh W, Rue PA, Polonsky KS, Yuan CS: Antidiabetic effects of Panax ginseng berry extract and the identification of an effective component. Diabetes 2002, 51(6):1851-1858

11. Lee TK, Johnke RM, Allison RR, O'Brien KF, Dobbs $L J$ Jr: Radioprotective potential of ginseng. Mutagenesis 2005, 20(4):237-243.

12. Xie JT, Mehendale SR, Li X, Quigg R, Wang X, Wang CZ, Wu JA, Aung HH, Rue PA, Bell GI, Yuan CS: Anti-diabetic effect of ginsenoside Re in ob/ob mice. Biochim Biophys Acta 2005, 1740(3):319-325.

13. Wang $H$, Peng D, Xie J: Ginseng leaf-stem: bioactive constituents and pharmacological functions. Chin Med 2009, doi:10.1186/1749-8546-4-20,

14. Peng L, Sun S, Xie L-H, Wicks SM, Xie J-T: Ginsenoside Re: Pharmacological Effects on Cardiovascular System. Cardiovascular Therapeutics 2011.

15. Lee SJ, Sung JH, Moon CK, Lee BH: Antitumor activity of a novel ginseng saponin metabolite in human pulmonary adenocarcinoma cells resistant to cisplatin. Cancer Lett 1999, 144(1):39-43.

16. Xie JT, Shao ZH, Vanden Hoek TL, Chang WT, Li J, Mehendale S, Wang CZ, Hsu CW, Becker LB, Yin JJ, et al: Antioxidant effects of ginsenoside Re in cardiomyocytes. Eur J Pharmacol 2006, 532(3):201-207.

17. Qi LW, Wang CZ, Yuan CS: American ginseng: potential structure-function relationship in cancer chemoprevention. Biochem Pharmacol 2010, 80(7):947-954

18. Shi YSC, Zheng B, Li Y, Wang Y: Simultaneous determination of nine ginsenosides in functional foods by high performance liquid chromatography with diode array detector detection. Food Chemistry 2010, 123:1322-1327

19. Gillis CN: Panax ginseng pharmacology: a nitric oxide link? Biochem Pharmacol 1997, 54(1):1-8.

20. Fuzzati N: Analysis methods of ginsenosides. J Chromatogr B Analyt Technol Biomed Life Sci 2004, 812(1-2):119-133.

21. Cheng $Y$, Shen LH, Zhang JT: Anti-amnestic and anti-aging effects of ginsenoside $\mathrm{Rg} 1$ and $\mathrm{Rb} 1$ and its mechanism of action. Acta Pharmacol $\sin 2005,26(2): 143-149$

22. Xie JT, Wang CZ, Wang AB, Wu J, Basila D, Yuan CS: Antihyperglycemic effects of total ginsenosides from leaves and stem of Panax ginseng. Acta Pharmacol Sin 2005, 26(9):1104-1110.

23. Li $X$, Sun J, Wang G, Hao H, Liang Y, Zheng Y, Yan B, Sheng L. Simultaneous determination of panax notoginsenoside R1, ginsenoside $\mathrm{Rg} 1, \mathrm{Rd}, \mathrm{Re}$ and Rb1 in rat plasma by HPLC/ESI/MS: platform for the pharmacokinetic evaluation of total panax notoginsenoside, a typical kind of multiple constituent traditional Chinese medicine. Biomed Chromatogr 2007, 21(7):735-746.

24. Ota T, Fujikawa-Yamamoto K, Zong ZP, Yamazaki M, Odashima S, Kitagawa I, Abe H, Arichi S: Plant-glycoside modulation of cell surface related to control of differentiation in cultured B16 melanoma cells. Cancer Res 1987, 47:3863-3867.

25. Banthorpe DV: Terpenoids. Natural Products. In. Essex: Longman Scientific and Technical 1994, 331-339.

26. Kim YS, Kim DS, Kim SI: Ginsenoside $\mathrm{Rh}_{2}$ and $\mathrm{Rh}_{3}$ induce differentiation of $\mathrm{HL}-60$ cells into granulocytes: modulation of protein kinase $\mathrm{C}$ isoforms during differentiation by ginsenoside $\mathrm{Rh}_{2}$. Int/ J Biochem Cell Biol 1998, 30:327-338.

27. Joo KM, Lee JH, Jeon HY, Park CW, Hong DK, Jeong HJ, Lee SJ, Lee SY, Lim KM: Pharmacokinetic study of ginsenoside Re with pure ginsenoside Re and ginseng berry extracts in mouse using ultra performance liquid chromatography/mass spectrometric method. J Pharm Biomed Anal 2010, 51(1):278-283.

28. Peng L, Sun S, Xie L-H, Wicks SM, Xie JT, Ginsenoside Re: Pharmacological effects on cardiovascular system. Cardiovasc Therap 2011, doi:10.1111/ j.1755-5922.2011.00271.x.

29. Xie JT, Aung HH, Wu JA, Attele AS, Yuan CS: Effects of American ginseng berry extract on blood glucose levels in ob/ob mice. Am J Chin Med 2002, 30(2-3):187-194.

30. Xie JT, Mehendale SR, Wang A, Aung HH, Wu J, Osinski J, Yuan C-S American ginseng leaf: Ginsenoside analysis and hypoglycemic activity. Pharmacol Res 2004, 49:113-117.

31. Li TSC, Mazza G, Cottrell AC, Gao L: Ginsenosides in roots and leaves of American ginseng. J Agric Food Chem 1996, 44:717-720.

32. Xie JT, Mehendale SR, Wang A, Han AH, Wu JA, Osinski J, Yuan CS: American ginseng leaf: ginsenoside analysis and hypoglycemic activity. Pharmacol Res 2004, 49(2):113-117.

33. Dharmananda S: The nature of ginseng: traditional use, modern research, and the question of dosage. Herbalgram 2002, 54:34-51.

34. Wang A, Wang CZ, Wu JA, Osinski J, Yuan CS: Determination of major ginsenosides in Panax quinquefolius (American ginseng) using highperformance liquid chromatography. Phytochem Anal 2005, 16(4):272-277.

35. Lim W, Mudge KW, Vermeylen F: Effects of population, age, and cultivation methods on ginsenoside content of wild American ginseng (Panax quinquefolium). J Agric Food Chem 2005, 53(22):8498-8505.

36. Shibata S, Tanaka O, Shoji J, Saito H: Chemistry and pharmacology of Panax. Economic and Medicinal plant Research 1985, 1:217-283.

37. Luchtefeld R, Kostoryz E, Smith RE: Determination of ginsenosides $R b_{1}, R c$, and $\mathrm{Re}$ in different dosage forms of ginseng by negative ion electrospray liquid chromatography-mass spectrometry. J Agric Food Chem 2004, 52(16):4953-4956

38. Xia C, Wang G, Sun J, Hao H, Xiong Y, Gu S, Shang L, Zheng C: Simultaneous determination of ginsenoside $\mathrm{Rg} 1, \mathrm{Re}, \mathrm{Rd}, \mathrm{Rb} 1$ and ophiopogonin $D$ in rat plasma by liquid chromatography/electrospray ionization mass spectrometric method and its application to pharmacokinetic study of 'SHENMAl' injection. J Chromatogr B Analyt Technol Biomed Life Sci 2008, 862(1-2):72-78.

39. Xie J-T, Attele AS, Yuan C-S: Ginseng: beneficial and potential adverse effect. In A textbook of complementary and alternative therapies. Edited by: Yuan C-S, Beiber E, Bauer BA. Boca Raton, London, New York, Washington, D.C.: CRC Press Company; 2006:71-89.

40. Kang SY, Schini-Kerth VB, Kim ND: Ginsenosides of the protopanaxatriol group cause endothelium-dependent relaxation in the rat aorta. Life Sciences 1995, 56(19):1577-1586.

41. Zhu GY, Li YW, Hau DK, Jiang ZH, Yu ZL, Fong WF: Protopanaxatriol-type ginsenosides from the root of Panax ginseng. J Agric Food Chem 2011, 59(1):200-205

42. Mizuno M, Yamada J, Terai H, Kozukue N, Lee YS, Tsuchida H: Differences in immunomodulating effects between wild and cultured Panax ginseng. Biochem Biophys Res Commun 1994, 200(3):1672-1678.

43. Leung KW, Wong AS: Pharmacology of ginsenosides: a literature review. Chin Med 2010, 5:20

44. Schlag EM, Mclntosh MS: Ginsenoside content and variation among and within American ginseng (Panax quinquefolius L.) populations. Phytochemistry 2006, 67:1510-1519.

45. Mihalov JJ, Marderosian AD, Pierce JC: DNA identification of commercial ginseng samples. J Agric Food Chem 2000, 48(8):3744-3752

46. Qu C, Bai Y, Jin X, Wang Y, Zhang K, You J, Zhang H: Study on ginsenosides in different parts and ages of Panax quinquefolius L. Food Chemistry 2009, 115:340-346.

47. Wu JM, Lin HY, Zhao LH, Jia HT, Jia HK, Wang Y, Chen DW: Comparative study on quality of Tongrentang red ginseng and Korean red ginsengdetermination of ginsenosides and polysaccharides. Zhongguo Zhong Yao Za Zhi 2007, 32(7):573-577.

48. Sritularak B, Morinaga O, Yuan CS, Shoyama Y, Tanaka H: Quantitative analysis of ginsenosides $\mathrm{Rb} 1, \mathrm{Rg} 1$, and Re in American ginseng berry 
and flower samples by ELISA using monoclonal antibodies. Nat Med (Tokyo) 2009, 63(3):360-363.

49. Morinaga O, Uto T, Yuan CS, Tanaka H, Shoyama Y: Evaluation of a new eastern blotting technique for the analysis of ginsenoside Re in American ginseng berry pulp extracts. Fitoterapia 2009, doi:10.1016/j. fitote.2009.10.005.

50. Lee M-J, Choi J-S, Cha S-W, Lee K-S, Lee Z-W, Hwang G-S, Lee SH, Kamal AHM, Jung Y-A, Seung N-S, Woo S-H: Variation in the ginsenoside profiles of cultivated ginseng (Panax ginseng C.A. Meyer) landraces in Korea. Process Biochemistry 2011, 46(1):258-264.

51. Hasegawa H: Proof of the mysterious efficacy of ginseng: basic and clinical trials: metabolic activation of ginsenoside: deglycosylation by intestinal bacteria and esterification with fatty acid. J Pharmacol Sci 2004, 95(2):153-157.

52. Christensen L: Ginsenosides: Chemistry, Biosynthesis, Analysis, and Potential Health Effects. Advances in Food and Nutrition Research 2008, 55:1-99.

53. Li X, Wang G, Sun J, Hao H, Xiong Y, Yan B, Zheng Y, Sheng L. Pharmacokinetic and absolute bioavailability study of total panax notoginsenoside, a typical multiple constituent traditional chinese medicine (TCM) in rats. Biol Pharm Bull 2007, 30(5):847-851.

54. Qi L-W, Wang C-Z, Yuan C-S: Isolation and analysis if ginseng: advances and challenges. Nat Prod Rep 2011, DOl: 10.1039/c0np000057d.

55. Han BH, Park MH, Han YN, Woo LK, Sankawa U, Yahara S, Tanaka O: Degradation of Ginseng Saponins under Mild Acidic Conditions. Planta Med 1982, 44(3):146-149.

56. Tawab MA, Bahr U, Karas M, Wurglics M, Schubert-Zsilavecz M: Degradation of ginsenosides in humans after oral administration. Drug Metab Despos 2003, 31:1065-1071.

57. Bae EA, Shin JE, Kim DH: Metabolism of ginsenoside Re by human intestinal microflora and its estrogenic effect. Biol Pharm Bull 2005, 28(10):1903-1908.

58. Chi H, Ji GE: Transformation of Ginsenosides Rb1 and Re from Panax ginseng by Food Microorganisms. Biotechnol Lett 2005, 27(11):765-771.

59. Chen G, Yang M, Guo D: Metabolic study of ginsenoside Re in rats. Zhongguo Zhong Yao Za Zhi 2009, 34(12):1540-1543.

60. Yang L, Xu S, Liu C, Su Z: In vivo metabolism study of ginsenoside Re in rat using high-performance liquid chromatography coupled with tandem mass spectrometry. Anal Bioanal Chem 2009, 395:1441-1453.

61. Liu YM, Yang L, Zeng X, Deng YH, Feng Y, Liang WX: Pharmacokinetics of ginsenosides Rg1 and Re in Shenmai injection. Yao Xue Xue Bao 2005, 40(4):365-368.

doi:10.1186/1749-8546-7-2

Cite this article as: Peng et al: Ginsenoside Re: Its chemistry, metabolism and pharmacokinetics. Chinese Medicine 2012 7:2.

\section{Submit your next manuscript to BioMed Central and take full advantage of:}

- Convenient online submission

- Thorough peer review

- No space constraints or color figure charges

- Immediate publication on acceptance

- Inclusion in PubMed, CAS, Scopus and Google Scholar

- Research which is freely available for redistribution

Submit your manuscript at www.biomedcentral.com/submit
Biomed Central 